\title{
Influence of Water-Repellent Treatment with Silicon Resin on Properties of Concrete
}

\author{
Yupeng Tian, ${ }^{1,2}$ Penggang Wang $\mathbb{D}^{1,2}$ Tiejun Zhao, ${ }^{1,2}$ Zhiming Ma, Zuquan Jin, ${ }^{3}$,2 \\ and Haitao Zhao iD ${ }^{4}$ \\ ${ }^{1}$ Engineering Research Center of Concrete Technology under Marine Environment, Ministry of Education, \\ Qingdao University of Technology, Qingdao 266033, China \\ ${ }^{2}$ Cooperative Innovation Center of Engineering Construction and Safety in Shandong Blue Economic Zone, \\ Qingdao 266033, China \\ ${ }^{3}$ College of Civil Science and Engineering, Yangzhou University, Yangzhou 225127, China \\ ${ }^{4}$ College of Civil and Transportation Engineering, Hohai University, Nanjing 210098, China \\ Correspondence should be addressed to Penggang Wang; wangpenggang007@163.com
}

Received 5 September 2018; Revised 11 January 2019; Accepted 30 January 2019; Published 26 February 2019

Academic Editor: Claudio Pettinari

Copyright (c) 2019 Yupeng Tian et al. This is an open access article distributed under the Creative Commons Attribution License, which permits unrestricted use, distribution, and reproduction in any medium, provided the original work is properly cited.

Although studies on water-repellent properties of silicon resin (SR) on cement-based materials have received tremendous attention around the world in recent years, they mainly focus on individual properties of water-repellent concrete treated with SR such as strength and water permeability resistance. However, to date, a systematic and comprehensive investigation is missing. The current study therefore investigates the influence of SR on the durability properties of cementitious materials by adding SR emulsion into integral concrete mixture and coating concrete surface with SR. The microscopic and mechanical properties and the durability performance were tested on the integral SR water-repellent concrete (C-ISR) and SR surface water-repellent concrete (C-SSR). The obtained results indicate that SR application has no impact on hydration reaction and corresponding composition of cement-based materials, while SR addition leads to a reduction in strength and early shrinkage of cement mortar because the added SR delays the hydration reaction. Water-repellent treatment via SR can significantly reduce the water permeability of concrete, which is more apparent for surface water-repellent treatment (SSR). Furthermore, the durability properties were investigated, and the results indicate that integral SR water-repellent treatment (ISR) possesses better properties than SSR, which suggests water-repellent treatment via surface coating as an effective means to improve concrete durability.

\section{Introduction}

Concrete is the most widely used building material in the world due to comparatively abundant source of raw materials and its easy-to-control shape. Application of reinforcements embedded in concrete has successfully improved the overall height and span of concrete buildings. Until recently, most people believed that natural concrete, especially high-strength concrete, offers the perfect function to protect internal steel bars. However, with continuous occurrence of steel corrosion and the resulting damage of concrete structure, it has gradually been realized that the use of high-quality concrete and appropriate thickness of protective layer as the first line of defense to improve durability may hardly guarantee the long-term durability of concrete. Because cementitious materials, as lacunary and hydrophilic materials, are prone to water permeation, the resulting effective transmission could transport aggressive chemical compounds and air pollutants (such as $\mathrm{CO}_{2}$ and chloride ion) into concrete. Concrete carbonation caused by $\mathrm{CO}_{2}$ from the atmosphere decreases the $\mathrm{pH}$ of pore solution to below 10, thus reducing the ability of concrete to protect embedded reinforcing bars from corrosion [1]. Chloride ions are known as a highly efficient catalyst for rebar corrosion [2]; therefore, in the salt-fog environment and at places where deicing salt is used, the invalidation of reinforced concrete structures caused by steel corrosion occurs often. In summary, preventing water ingress into concrete 
can effectively improve the durability of concrete. To avoid corrosion damage, especially in the marine environment, additional anticorrosion measures should still be adopted.

Silane, generally refers to silane and siloxane-based repellence agents, can eliminate hydroxyl in cementitious composites, making the concrete hydrophobic; however, they simultaneously retain breathability compared to sealing waterproofing or other physical waterproofing. Additionally, these water repellents are characterized by relatively longtime durability due to their capability to react with the cement matrix and because of their excellent ultraviolet, alkali, and acid stability [3]. Silane-based repellent agents can be added to fresh concrete during the fabrication process, making the cement-based integrally water-repellent concrete. Numerous studies have been conducted to evaluate the mechanical properties of integral silane-based water repellents. The obtained results led to the conclusion that the mechanical strength of cementitious materials may be slightly decreased by addition of silane [4]. The reason may be due to the presence of silane influencing the reaction between water and $\mathrm{C}_{3} \mathrm{~S}$; furthermore, reduction of water uptake by the addition of emulsions has been assessed and also its impact on hydration of cement at an earlier stage [5]. However, lowering the water-cement ratio can compensate for the associated modest strength reduction, which has been reported by $\mathrm{Li}$ et al. [6]. Although silane-based water repellent can decrease the mechanical properties of cementbased materials, for structures without high strength requirements, this disadvantage can be ignored.

Many investigations reported the influence of silane emulsion on the durability properties, such as water capillary suction and chloride penetration. It was reported that capillary suction can be significantly reduced by up to 89-93\% [7-9]. Furthermore, it was reported that an addition of than $2 \%$ (relative to cement mass) of silane emulsion greatly reduced the chloride penetration of concrete so that the chloride penetration depth for integral water samples could be reduced by one-third compared to plain concrete [10]. In addition, silane can also be used to coat the exposed concrete surface to protect it from attacks by foreign agents. Surface treatment of cementitious materials with silane and siloxane oligomer-based water repellents has been considered as a reliable method to protect concrete from ingress of aggressive solution [11-15]. It has been reported that surface water-repellent treatment is more efficient $[9,16]$.

Previous investigations have demonstrated silane or siloxane water repellency is a reliable, long lasting solution that minimizes water penetration within inorganic construction material $[17,18]$. Nevertheless, a variety of waterrepellent materials would meet the requirement of the construction industry better, and few studies have systematically studied silicone resin (SR), which consists of highly branched polysiloxanes of high molecular weight. As a further research on waterproofing of silicone materials, the objective of this study is to systematically investigate the influence of SR on the resulting durability of concrete. Two types of concrete were prepared for this experiment: integral SR treatment concrete (C-ISR) was prepared by adding different dosages of SR into fresh concrete admixtures and surface SR treatment concrete (C-SSR) was prepared via surface impregnation with different dosages of SR. Firstly, the influence of SR on hydration products and hydration process was evaluated by adding SR into concrete mixtures. Then, the durability properties of SR on concrete were investigated via a capillary suction test, an accelerated carbonation experiment, and a chloride penetration test. Additionally, the resulting air permeability of both types of water-repellent treatments was evaluated.

\section{Materials and Experimental Details}

2.1. Mixture Proportions and Concrete Specimens. Portland cement Type I (CEM I, 42.5) with the chemical composition of cement shown in Table 1 is used in this study. Aggregates were crushed to a maximum diameter of $20 \mathrm{~mm}$. Natural river sand with a maximum diameter of $5 \mathrm{~mm}$ has been used throughout. A water to cement (w/c) ratio of 0.5 has been used for all specimens used in this study, and no other plasticizers were added. Compositions and proportion of the utilized concrete are listed in detail in Table 2. A typical polyalkyltrialkoxysiloxane (with a ratio of $n$-octylmethoxysilane to $n$-propyltrimethoxysilane of $1: 1$ ) emulsion (SR) was used. The active ingredient in the emulsion is $30 \%$, and the average particle size is $4.406 \mu \mathrm{m}$. Four types of integral SR water-repellent concrete (or cement mortar) specimens were prepared by adding $0 \%, 1 \%, 2 \%, 3 \%$, and $4 \%$ (by the weight of cement mass) into fresh concrete (or cement mortar). It is worth mentioning that the fluidizing capability of both the fresh concrete mixture and cement paste increased with the addition of SR, which is consistent with the results reported for silane $[7,16]$. The compressive and bending strength of mortar were measured at the curing ages of 3 days, 7 days, 14 days, and 28 days. For the surface water-repellent treatment, five SRs (with the dosages of $100 \mathrm{~g} / \mathrm{m}^{2}, 200 \mathrm{~g} / \mathrm{m}^{2}$, $300 \mathrm{~g} / \mathrm{m}^{2}, 400 \mathrm{~g} / \mathrm{m}^{2}$, and $600 \mathrm{~g} / \mathrm{m}^{2}$ ) were used to uniformly coat the forming surface of concrete specimens. Then, the specimens were stored in the lab environment at around $20 \pm 3^{\circ} \mathrm{C}$ and $60 \% \mathrm{RH}$ for a further week prior to the experiment to ensure adequate reaction of SR and cement.

Two types of prismatic concrete specimens with the dimensions of $100 \times 100 \times 100 \mathrm{~mm}$ and $100 \times 100 \times 400 \mathrm{~mm}$ and one type of mortar specimen of $40 \times 40 \times 160 \mathrm{~mm}$ were prepared. The specimens were stored at a standard curing room $\left(20^{\circ} \mathrm{C}, \mathrm{RH}>95 \%\right)$ until 28 days after shaping and demolding. Moreover, prismatic concrete samples were using for capability suction and were prepared by cutting $100 \times 100 \times 100 \mathrm{~mm}$ concrete, at a curing age of 14 days, into two halves along the pouring surface. The obtained $50 \times 100 \times 100 \mathrm{~mm}$ prismatic concrete samples were maintained for further 14 days.

2.2. Microscopic Test. To investigate the effect of SR on the obtained hydration products and the composition of cement, hardened cement pastes (also $0.5 \mathrm{w} / \mathrm{c}$ ) either with and without SR were first fractured into small pieces and then ground with a pestle until the powder passed a $80 \mu \mathrm{m}$ sieve before predrying at $55^{\circ} \mathrm{C}$ for $24 \mathrm{~h}$. Thermogravimetric 
TABLE 1: Chemical composition of cement (\%).

\begin{tabular}{lccccccccc}
\hline Chemical composition & $\mathrm{SiO}_{2}$ & $\mathrm{Fe}_{2} \mathrm{O}_{3}$ & $\mathrm{Al}_{2} \mathrm{O}_{3}$ & $\mathrm{CaO}$ & $\mathrm{MgO}$ & $\mathrm{SO}_{3}$ & $\mathrm{~K}_{2} \mathrm{O}$ & $\mathrm{Na}_{2} \mathrm{O}$ & $\mathrm{TiO}_{2}$ \\
\hline P.O 42.5 & 20.07 & 2.93 & 5.09 & 61.71 & 1.58 & 1.99 & 0.36 & 0.70 & 0.34 \\
\hline
\end{tabular}

TABLE 2: Concrete mixture proportions $\left(\mathrm{kg} / \mathrm{m}^{3}\right)$.

\begin{tabular}{|c|c|c|c|c|c|c|}
\hline Specimens & $\mathrm{w} / \mathrm{b}$ & Cement & Water & Sand & Natural aggregates & SR \\
\hline C-ISR-0\% SR & & & 160 & & & 0 \\
\hline C-ISR-1\% SR & & & 157.8 & & & 3.2 \\
\hline C-ISR-2\% SR & 0.5 & 320 & 155.5 & 653 & 1267 & 6.4 \\
\hline C-ISR-3\% SR & & & 153.3 & & & 9.6 \\
\hline C-ISR- $4 \%$ SR & & & 151 & & & 12.8 \\
\hline
\end{tabular}

analysis (TGA) measurement of the samples was performed via heating from $0^{\circ} \mathrm{C}$ to $1000^{\circ} \mathrm{C}$ at a heating rate of $10^{\circ} \mathrm{C} / \mathrm{min}$ under nitrogen atmosphere. X-ray diffraction (XRD) is a further useful method for semiquantifying the content of hydration products. Scanning electron microscope (SEM) data were collected with measurements ranging from $10^{\circ}$ to $50^{\circ} \theta$ with a $0.01^{\circ} 2 \theta$ step size. SEM was conducted to observe the surface morphology of C-SSR in response to different dosages of SR. The presented SEM results show the formed surface of concrete specimens $(\mathrm{w} / \mathrm{c}=0.5)$.

2.3. Mechanical and Shrinkage Experiments. Cement mortar prisms $(40 \times 40 \times 160 \mathrm{~mm})$ with ISR used for the autogenous shrinkage test were wrapped in an inner layer of plastic and an outer layer of aluminum foil and then sealed with an aluminum tape. This test has been performed according to the method reported in the JGJ/T70-2009 standard for China. The testing method involved the measurement using a length comparator of the linear dimension variation of the cement mortar prism along the longitudinal axis. Both initial mass and length of cement mortar prisms were measured after $28 \mathrm{~d}$ of curing. Then, the cement mortar prisms were transferred to laboratory conditions at $20 \pm 3^{\circ} \mathrm{C}$. The autogenous shrinkage was measured after $1 \mathrm{~d}, 3 \mathrm{~d}, 7 \mathrm{~d}, 14 \mathrm{~d}$, and $28 \mathrm{~d}$ and then every other month. To ensure accuracy, a length comparator, with a precision of $0.001 \mathrm{~mm}$, was applied and the obtained values were averaged based on at least three measured values. The shrinkage strain of the cement mortar prism was calculated according to the following equation:

$$
\varepsilon_{t}=\frac{L_{0}-L_{t}}{L_{0}}
$$

where $\varepsilon_{t}$ represents the shrinkage strain value at time $t, t$ represents the time interval from the beginning of the first measurement, $L_{0}$ represents the initial length of the specimen, and $L_{t}$ represents the length of the specimen at time $t$.

Higher curing temperatures, at equal degrees of hydration, may produce lower shrinkage since a larger volume and coarser distribution of capillary porosity are produced at higher curing temperatures [19]. The drying temperature used in this test was $20 \pm 3^{\circ} \mathrm{C}$.

2.4. Test of Durability Performance. The water capillary absorption test has been performed following the partial immersion method described in the ISO standard [20]. Except for the cutting surface and its opposite side, the other four specimen surfaces were sealed with paraffin wax, ensuring one-dimensional transmission. After the SR was evenly distributed on the surface, C-SSRs were prepared via drying at a temperature of $50^{\circ} \mathrm{C}$ for $7 \mathrm{~d}$ until mass equilibrium was reached. When the specimens cooled down to room temperature, the forming face was brought in contact with either water or $\mathrm{NaCl}$ solution. The amount of absorbed water was determined by weighing the C-SSRs after different immersion durations. The capillary absorption process can be described as a function of time, as shown in equation (2). However, due to many influencing factors in the capillary absorption process, as for instance gravity, evaporation, and skin effect, this relationship is only valid for limited time intervals. Therefore, the initial coefficient of capillary absorption will be used to describe the capillary of concrete:

$$
A=\frac{\Delta \mathrm{W}}{\sqrt{t}}
$$

where $A$ represents the coefficient of capillary suction (g/ $\mathrm{m}^{2} \cdot \mathrm{h}^{1 / 2}$ ) and $\Delta \mathrm{W}$ represents the amount of water absorbed per unit of surface $\left(\mathrm{g} / \mathrm{m}^{2}\right)$ via capillary action as a function of time $t(\mathrm{~h})$.

To study the surface wettability, the water contact angle (CA) of C-ISR and C-SSR were determined using a goniometer. A large number of studies reported that the causes of contact angle hysteresis can be roughly divided into two categories: thermodynamic [21] and dynamic [22]. Thermodynamic hysteresis is caused by both surface roughness and chemical diversity [23], which generates droplets in a metastable state and causes hysteresis [24]. To circumvent this, the contact angle was measured with deionized water at a moment of $30^{\circ} \mathrm{s}$ in the experimental environment to characterize the hydrophobicity. The average value of the water contact angle was determined by at least three test points.

Chloride-caused corrosion is a major factor that leads to invalidation of concrete structures in the marine environment and in places where deicing salt is used. The penetration rate of chloride is also an important parameter for the estimation of the service life of reinforced concrete structures. Both the C-ISR and C-SSR were sealed and immersed in $0.5 \% \mathrm{NaCl}$ solution and subjected to capillary suction. The resulting chloride profiles have been experimentally determined via successively milling of thin layers from the 
surface. Then, the concentration and penetration depth of the chloride ion on the surface of the test concrete were obtained via chemical titration.

Accelerated carbonation is a process during which $\mathrm{CO}_{2}$ is intentionally introduced to concrete to simulate the carbonization process in the real environment [25]. Firstly, specimens $(100 \times 100 \times 400 \mathrm{~mm})$ with ISR and SSR were dried via capillary suction since $\mathrm{CO}_{2}$ in the air is first dissolved in the pore solution and the ultimate carbonization depth values varied if specimens had different moisture content. Four surfaces $(100 \times 400 \mathrm{~mm})$ of concrete specimens were sealed with epoxy resin; then, two opposite sides $(100 \times 100 \mathrm{~mm})$ were used to measure carbonation depth. C-ISR and C-SSR were mixed in a carbonization box (RH. $75 \pm 5 \%, 20 \pm 1^{\circ} \mathrm{C}$ ) and the concentration of $\mathrm{CO}_{2}$ is approximately $20 \pm 2 \%$. After $3 \mathrm{~d}, 7 \mathrm{~d}, 14 \mathrm{~d}$, and $28 \mathrm{~d}$, the specimens were split from the carbonized surface. The method of determining the depth of carbonation is by spraying phenolphthalein indicator on the surface of a freshly split concrete prism. Because the fully carbonated paste has a $\mathrm{pH}$ below 10 , the reaction depth can be easily obtained with phenolphthalein indicator solution. The value of the carbonation depth presented is the average value at six different positions.

The air permeability test was conducted on the forming surfaces of specimens using the Autoclam device. Because the internal relative humidity condition of concrete has great interference on the permeability [26], both C-ISRs and C-SSRs were dried ahead of test. The pressure inside the apparatus was increased to $5 \times 10^{4} \mathrm{~Pa}$, and the pressure decay was monitored every minute for $15 \mathrm{~min}$. The natural logarithm plot of pressure against time was linear; hence, the slope of the linear regression curve between 6th and 15th minute of the test was defined as the air permeability index (API), with the unit of Ln (pressure)/min. This metric was used to evaluate the effectiveness of surface treatments in this test.

\section{Results and Discussion}

3.1. Microscopic Behavior Analysis of SR-Treated Concrete. XRD and TGA were used to either quantitatively or qualitatively characterize the cement hydration product in hardened cement pastes with a w/c of $0.5[27,28]$. Figure 1 summarizes the data obtained from TGA of the cement paste at various dosages of SR. Figure 1 shows that the diffraction peaks are in the same position, which indicates that the addition of SR did not generate new crystals, with an amount of $4 \%$. The dotted line represents the thermogravimetric curve (TG curve), and the solid line represents the heat flux curve (DTG curve). Comparing both curves shows that there are approximately three stages of mass loss in a continuous process.

For the first stage, during the temperature of $100-200^{\circ} \mathrm{C}$, due to water absorption during cement paste vaporization, the quality of the sample is continuously decreased. Furthermore, the water evaporation process can absorb heat energy. For the second stage, during a temperature of $400-450^{\circ} \mathrm{C}$, the curve decreases due to the decomposition of

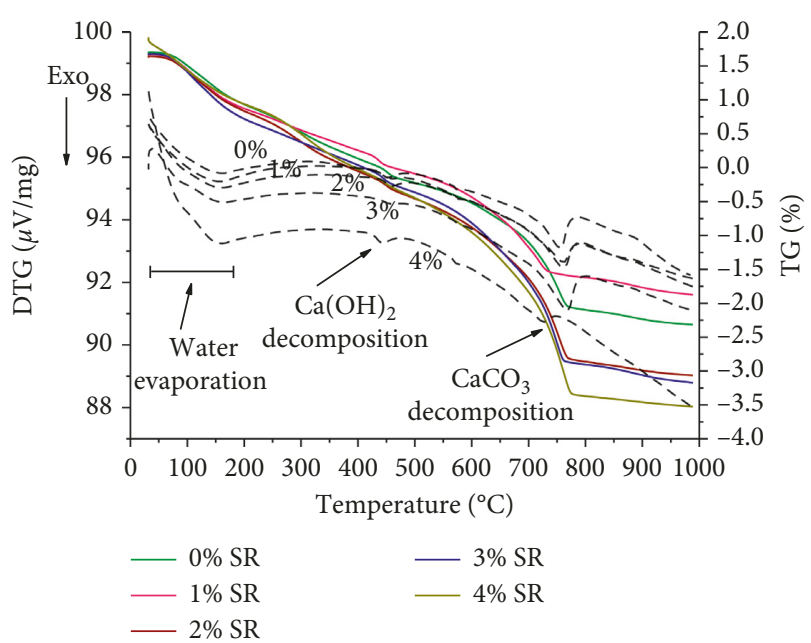

FIGURE 1: TGA result of cement pastes with different dosages of SR.

$\mathrm{Ca}(\mathrm{OH})_{2}$. For the third stage, during a temperature of $750-800^{\circ} \mathrm{C}$, the endothermic peak observed at about $750^{\circ} \mathrm{C}$ on the two curves is due to the decomposition of $\mathrm{CaCO}_{3}$. However, with regard to SR admixtures, in addition to weight loss, an additional decomposition process of small molecules was observed, which are unreacted components during emulsion polymerization under $500^{\circ} \mathrm{C}$. For a temperature above $500^{\circ} \mathrm{C}$, additional fractures of Si-C condensation of Si-OR and $\mathrm{Si}-\mathrm{OH}$ appeared. Based on the above analyses, fresh chemical bonds between SR and cementbased materials did not form in hydration, that is, SRs have no effect on hydration products.

SEM was employed to investigate the morphology of the C-SSRs with various amounts of SR at a curing age of $28 \mathrm{~d}$. Because all SEM images were captured from the surface of specimens, the typical hydration products of cement are hardly visible. Under 3000X magnification, the surface of concrete is porous, rough, and flaky; however, for specimens in the presence of SR, the surface gradually compacts (Figure 2). Beyond a coating amount of $400 \mathrm{~g} / \mathrm{m}^{2}$, the surface morphology of concrete greatly changed and the holes on the concrete surface are noticeably reduced. This indicates that, after the SR surface coating amount reaches a certain level, the mechanism to prevent water from entering concrete not only makes concrete water repellent but also seals the concrete surface. This can be also proved by the result of the Autoclam test. This characteristic is closer to other resin sealing materials, such as epoxy resin.

\subsection{Mechanical and Shrinkage Properties of SR-Treated} Concrete. Figure 3 presents the results of compressive strength and bending strength. Adding SR reduces the mechanical strength of concrete. At a curing age of $28 \mathrm{~d}$, the flexural strength of concrete specimens prepared with $4 \%$ SR decreased by approximately $10 \%$ compared to reference concrete. The compressive strength of prismatic specimens at dosages of $4 \%$ decreased by approximately $26 \%$ compared to plain concrete. This result is better than the effect of silane and siloxane oligomer-based waterproof materials where 


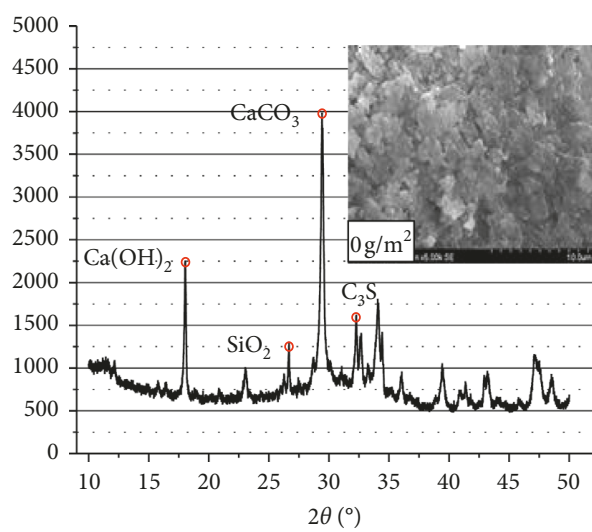

$-0 \%$

(a)

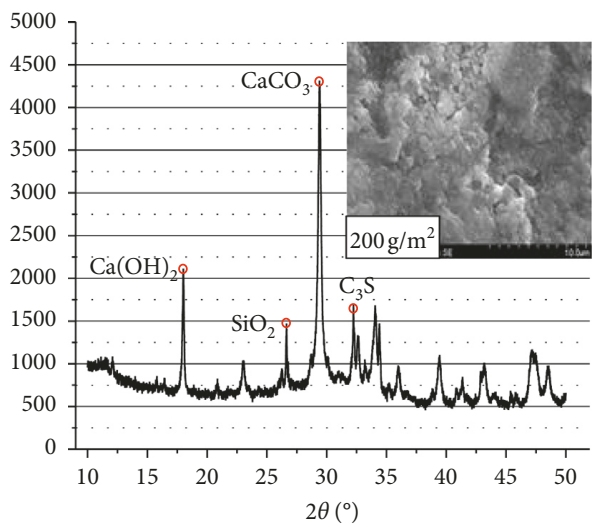

$-2 \%$

(c)

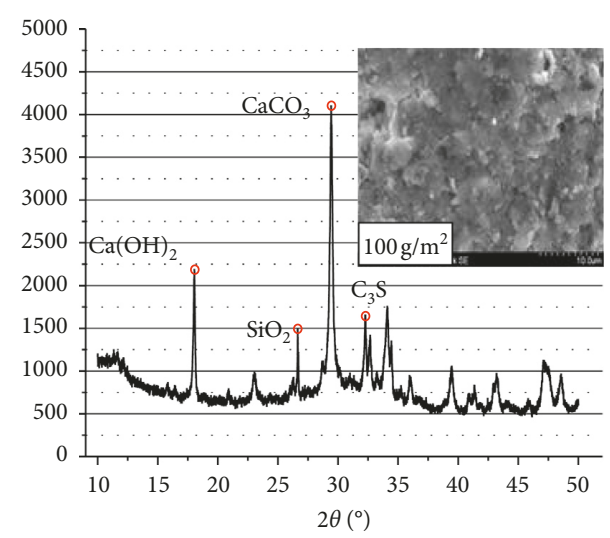

$-1 \%$

(b)

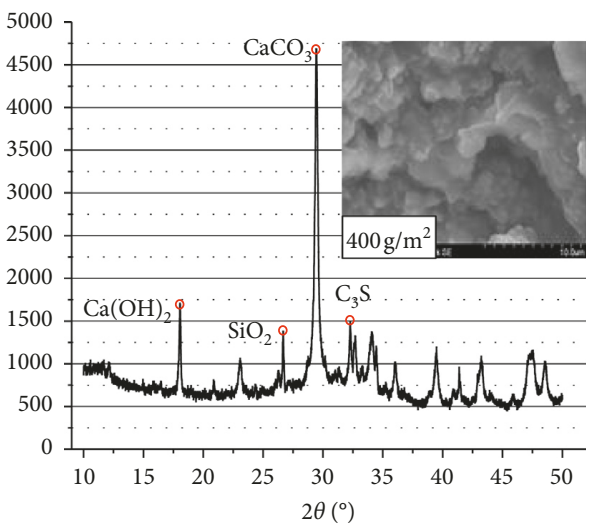

(d)

Figure 2: Composition and microstructure analysis via X-ray and SEM. (a) $0 \%$. (b) $1 \%$. (c) $2 \%$. (d) $4 \%$.

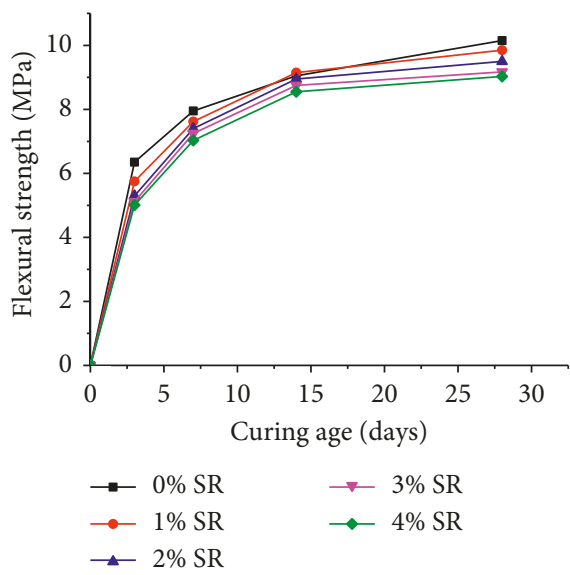

(a)
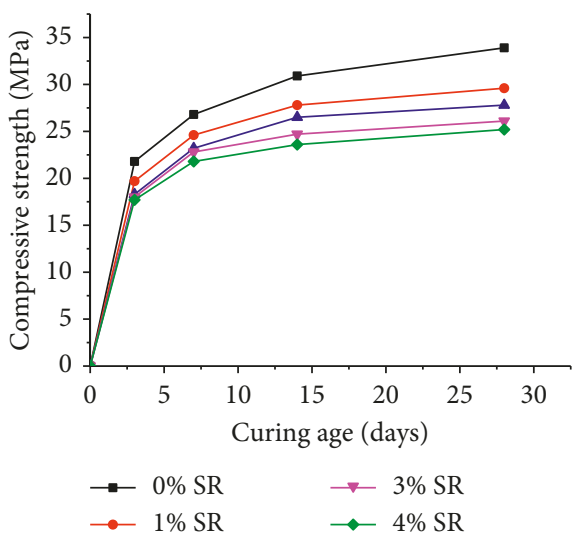

(b)

FIgURE 3: Mechanical properties of concrete with various SR contents. (a) Compressive strength. (b) Bending strength.

$4 \%$ SR decrease by approximately $1 / 3$ in previous studies $[10,20]$. Moreover, both the flexural strength and compressive strength of concrete significantly decreased in response to SR addition. This decrease of compressive strength and bending strength is likely because during the further hydrolysis of SR, the reactive silanol groups anchor to the cement matrix or to the aggregate, leading to hydrophobic surfaces. The contact of water and cement active substance is 
blocked; accordingly, the degree of hydration of cementbased materials is decreased [29].

Dynamic shrinkage curves, based on transient (i.e., nonequilibrium) shrinkage, are shown in Figure 4. The results show that the cumulative autogenous shrinkage for all cement mixes increases with a shrinkage duration of $196^{\circ} \mathrm{h}$. Addition of SR slightly delays mortar shrinkage as expected because SR can delay the hydration of cement in which active ingredients are the main causes of shrinkage. SR noticeably reduces the early stage shrinkage of cement, but with ongoing curing, the intensity difference between mortar with and without SR will gradually decrease. However, this seems to be a long-term process since at a drying time of $200^{\circ} \mathrm{d}$, a remarkable difference was found. Whether SR reduces the final contraction is a new concept that requires further investigation. Although SR reduces the mechanical strength of cement-based material, it also compensates for early shrinkage, which is an advantage in engineering applications.

The histogram shown in Figure 5 corresponds to the average shrinkage values of drying at different humidity levels. Firstly, this indicates that the drying humidity noticeably influences the velocity of early time moisture diffusion. By the end of the experiment, $4 \%$ of specimens at a drying humidity of $65 \%$ and $80 \%$ reduced by $38 \%$ and $61 \%$ compared to $50 \%$, respectively. This can be explained by the second law of Ficker, which indicates that the rate of water loss per unit time is related to the concentration difference between the inside and the outside of concrete. SR addition will slightly reduce the drying shrinkage. The mechanism of drying shrinkage can be explained via capillary stress, surface free energy, and separation pressure. Capillary stress and separation pressure are the main reasons for shrinkage between 100 and 40\% relative humidity [30]. The GibbsBangham (free surface energy) effect operates at lower relative humidity (below 40\%) [10, 29, 31]. SR reduces the surface free energy of cement particles and also reduces the ability of grasping moisture. Addition of SR not only affects the hydration process of cement, thus preventing shrinkage, but also increases the free water content in cement mortar pores compared to neat cement, which promotes the shrinkage of cement.

3.3. Durability Performance of SR-Treated Concrete. The results listed in Table 3 indicate that two methods can both reduce water absorption at varying degrees. After 3\% SR integral treatment, the capillary absorption coefficient is significantly reduced by approximately $45.6 \%$ compared to reference concrete. However, addition dosages below 3\% are not the optimum. This is because the effective continuous SR waterproof network cannot be formed when the emulsion is scarce. Compared to C-ISR, C-SSR showed a more significant effectiveness (Figure 6). The capillary water absorption coefficients of $400 \mathrm{~g} / \mathrm{m}^{2}$ and $600 \mathrm{~g} / \mathrm{m}^{2}$ decreased by $87.7 \%$ and $91.7 \%$, respectively, when compared to plain concrete. This is in good agreement with silane and siloxane oligomer-based water-repellent agents where the integral SR water-repellent treatment was less

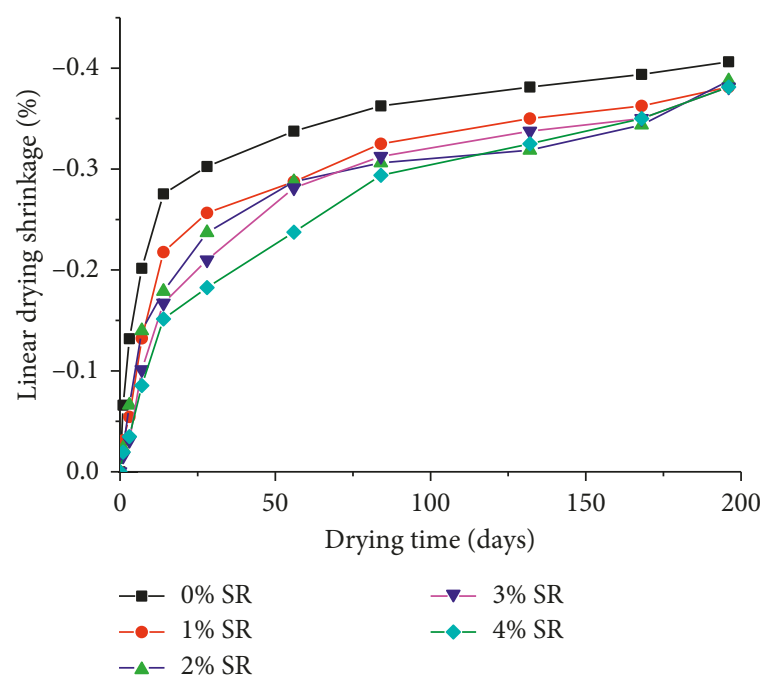

FIgURE 4: Autogenous deformation versus time for 200 days for mortar mixtures with various SR contents.

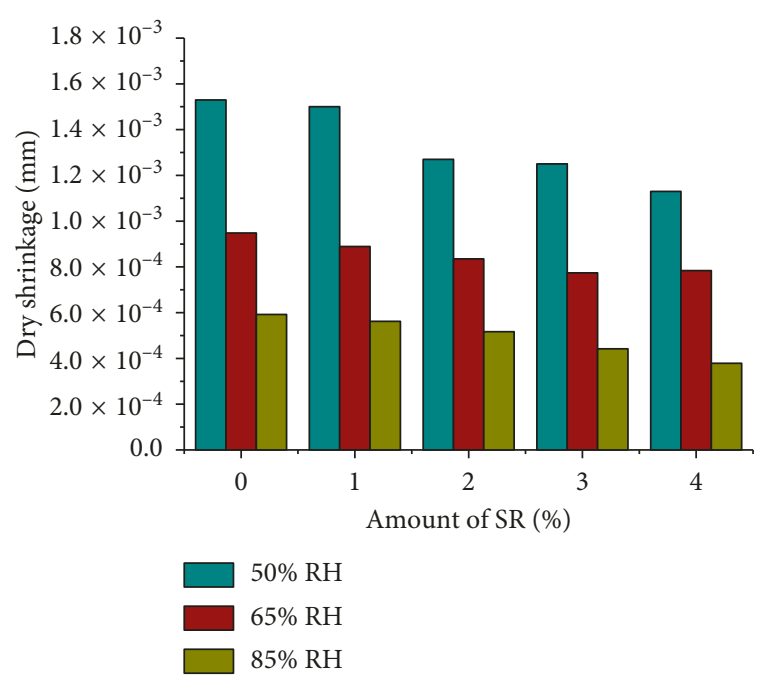

FIGURE 5: Dry shrinkage value of concrete with various SR contents at 200 days.

efficient in repelling water when compared to surface water-repellent treatments $[13,32]$.

The reaction process between SR and cement-based materials can be described as follows. When SR emulsion is exposed to cement or aggregate, emulsion is first broken and then SR dehydrates and condenses on the pore surface of the cement-based material; then, the high-crosslinking SR waterproof membrane is formed (in Figure 7). Surface water-repellent treatment by high amount of SR may prevent most of the water from entering into the concrete; however, even higher amounts cannot entirely prevent water from entering concrete, mainly due to the following reasons: the size of emulsion particles (according to the laser granularity analyzer, the average particle size of SR emulsion was $4.406^{\circ} \mu \mathrm{m}$ ) exceeds that of the aperture of millipore in the C-S-H gel [33]; therefore, the SR emulsion molecules do not affect nanometer-sized holes, shown in Figure 8. 
TABLE 3: Capillary water absorption coefficient and decrease rate of C-ISR and C-SSR.

\begin{tabular}{|c|c|c|c|c|c|c|c|c|c|c|}
\hline Amount of added SR & Plain & $1 \%$ & $2 \%$ & $3 \%$ & $4 \%$ & $100 \mathrm{~g} / \mathrm{m}^{2}$ & $200 \mathrm{~g} / \mathrm{m}^{2}$ & $300 \mathrm{~g} / \mathrm{m}^{2}$ & $400 \mathrm{~g} / \mathrm{m}^{2}$ & $600 \mathrm{~g} / \mathrm{m}^{2}$ \\
\hline Capillary absorption coefficient & 523.4 & 450.5 & 384.0 & 285.6 & 282.4 & 205.2 & 131.1 & 124.3 & 64.4 & 43.4 \\
\hline Decrease rate (\%) compared to plain concrete & - & 13.9 & 26.6 & 45.4 & 46.0 & 60.8 & 75.0 & 76.3 & 87.7 & 91.7 \\
\hline
\end{tabular}

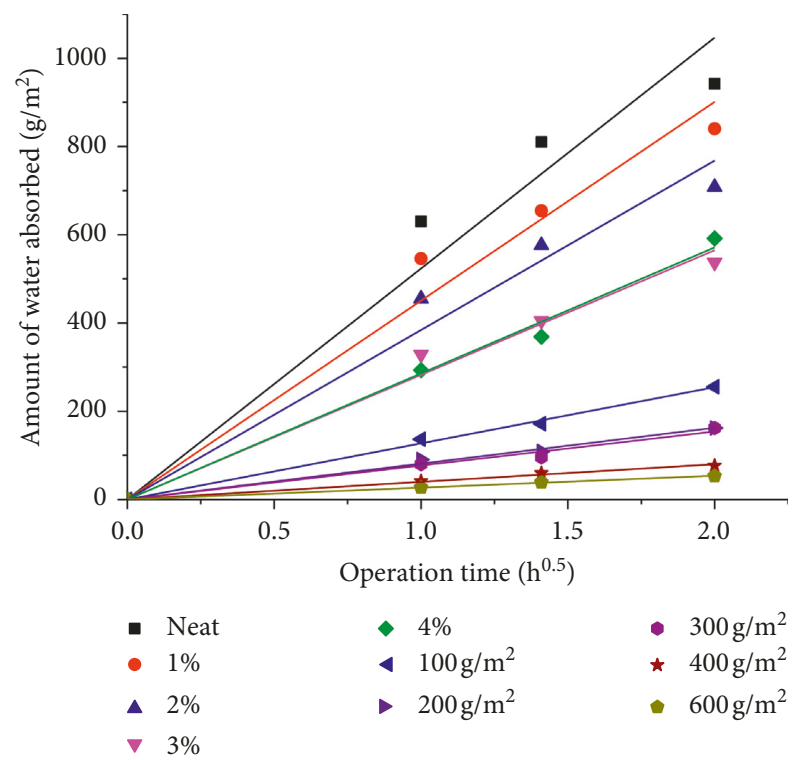

FIGURE 6: Capillary water absorption of concrete with various SR contents.

The surface energy of concrete represents the ability to repel static water and can be investigated by the water contact angle. A contact angle above $90^{\circ}$ indicates that the surface free energy of concrete is low and hydrophobic. Due to the hydrolysis of alkoxyl groups to hydroxyl groups and the subsequent condensation with hydroxyl groups in mortar, silane and siloxane oligomer-based water repellents can eliminate hydroxyl of concrete and make concrete hydrophobic (Figure 7); however, they may not influence the final chemical products [3]. Exemplary images of water droplets on the surface of C-ISR and of C-SSR are shown in Figures 9 and 10. All results of the contact angle were picked up at $30^{\circ}$ s after water droplets contact concrete to neglect the contact angle hysteresis. As expected, the surface tension gradually reduced with an increase of SR. An addition of $1 \%$ will make the surface hydrophobic. With increasing silicon content, the contact angle values ranged from $95^{\circ}$ to $118^{\circ}$. The result of $4 \%$ SR is close to the result of surface waterproofing treatment that obtained angles from $104^{\circ}$ to $136^{\circ}$. This can be explained because during the first drying, the SR emulsion migrates towards the concrete surface. Surface tension describes the ability of the surface treatment to expel water. When water comes into contact with a porous material, capillary forces are developed (according to the Washburn equation) that drives water through pores [34]. The concrete surface tension can be investigated with the water contact angle.

The resulting chloride profiles are shown in Figures 11 and 12, which represent the approximate value of the chloride ion content. Figure 11 shows that more than $2 \%$ SR addition can effectively prevent the penetration of chloride into concrete. The chloride penetration depth in the test specimens with $4 \%$ content was reduced by $1 / 3$. Surprisingly, after the addition of $1 \%$ SR emulsion, the coefficient of capillary suction decreased, as shown in Table 2, while the chloride ion invasion increased slightly. This is because the presence of SR emulsion impedes normal hydration so that pores in this type of concrete are wider than those in plain concrete, thus resulting in a slight increase in chloride penetration. Wittmann considered this as the results of filtration in the process of water migration [35, 36].

Because ions surrounded by hydrated shells are too large to pass through the nanostructures of hardened cement pastes, during the infiltration process, pure water is at the front and ions are at the rear. When the amount of addition reaches $3-4 \%$, the penetration depth and content of chloride ions are noticeably reduced; however, the obtained ion curve is not smooth, which is because the one emulsion is insufficient to form a continuous waterproofing layer, and the waterproofing ability is different at different depths. The result of chloride profiles with SSR is shown in Figure 12. An overall observation is that surface waterproofing can distinctly reduce chloride penetration. $400 \mathrm{~g} / \mathrm{m}^{2}$ surface treatment penetration depth of chloride ions is only approximately $7 \mathrm{~mm}$ and is reduced by $1 / 3$ compared to plain specimens.

$\mathrm{CO}_{2}$ can neutralize the alkalinity of concrete and remove the passivated film of rebar, thus reducing the service life of concrete structures. Carbonation is the result of $\mathrm{CO}_{2}$ dissolving in concrete pore fluids and reacting with calcium, which originates from calcium hydroxide and calcium silicate hydrate, thus forming calcite $\left(\mathrm{CaCO}_{3}\right)$ [37]. Figures 13 and 14 present the result of carbonization depth of concrete at ages of up to $28 \mathrm{~d}$. This shows that during all test ages, carbonation depth of concrete decreased with increasing SR dosage, regardless of whether C-ISR or C-SSR were investigated. However, the result of the first waterproofing method is not obvious. $4 \%$ of SR addition only reduces $18 \%$ of carbonization depth, while this is only more than $1 \mathrm{~mm}$ at ages of up to $28 \mathrm{~d}$. Moreover, compared to ISR, even $100 \mathrm{~g} / \mathrm{m}^{2}$ of SSR has a noticeable waterproofing effect. When the coating amount is $600 \mathrm{~g} / \mathrm{m}^{2}$, at the age of $28 \mathrm{~d}$, the carbonization depth is reduced by $68.8 \%$, which is about four times compared to $4 \%$ SR addition (18\%). This may be due to a difference in waterproofing effect [38] and in air permeability.

Table 4 provides the air permeability indexes (API) between 6 and $15 \mathrm{~min}$. Compared to untreated specimens, the air permeability of specimens treated with SR may be slightly decreased. With regard to ISR, when the content of SR reaches $4 \%$, the air permeability decreases by more than $33.8 \%$ compared to plain concrete. However, the air permeability of concrete can be influenced by a high dosage of 


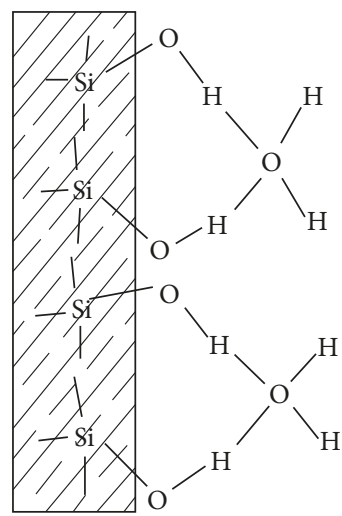

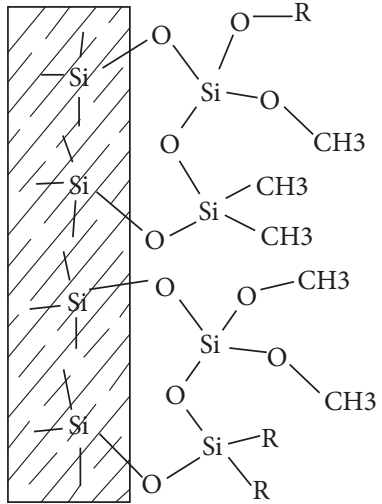

(a)

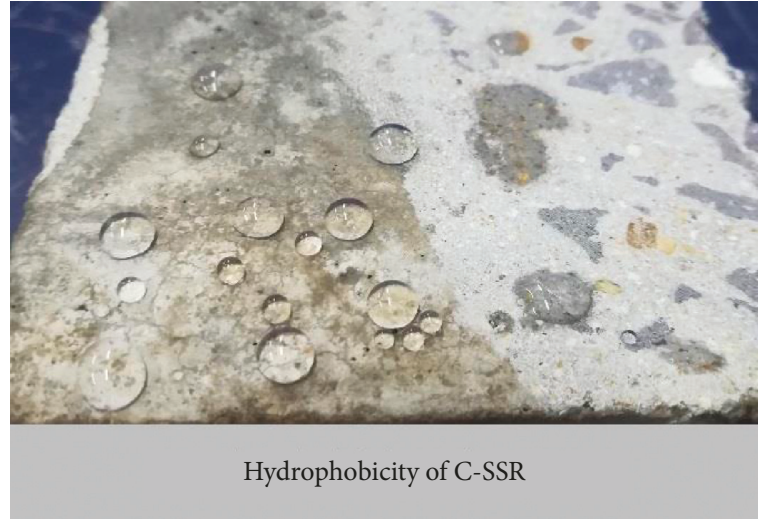

(b)

FIGURE 7: SR reaction mechanism leading to concrete hydrophobisation.

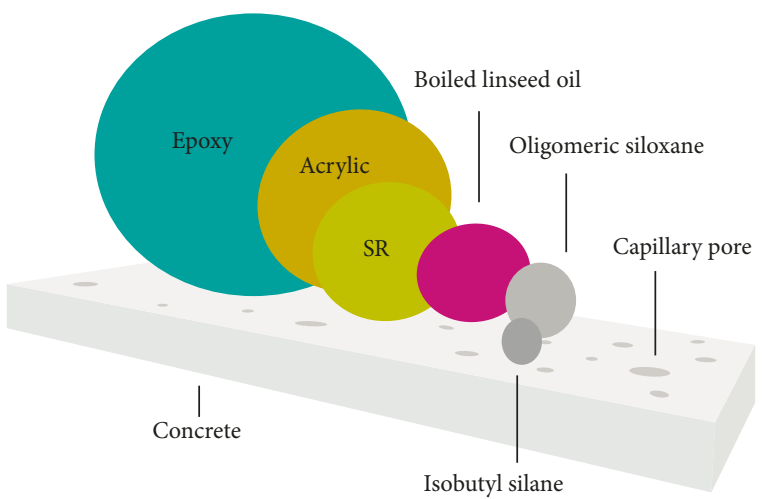

Figure 8: Diagrammatic representation of molecular size of different hydrophobic agents in comparison with the capillary pores of concrete.

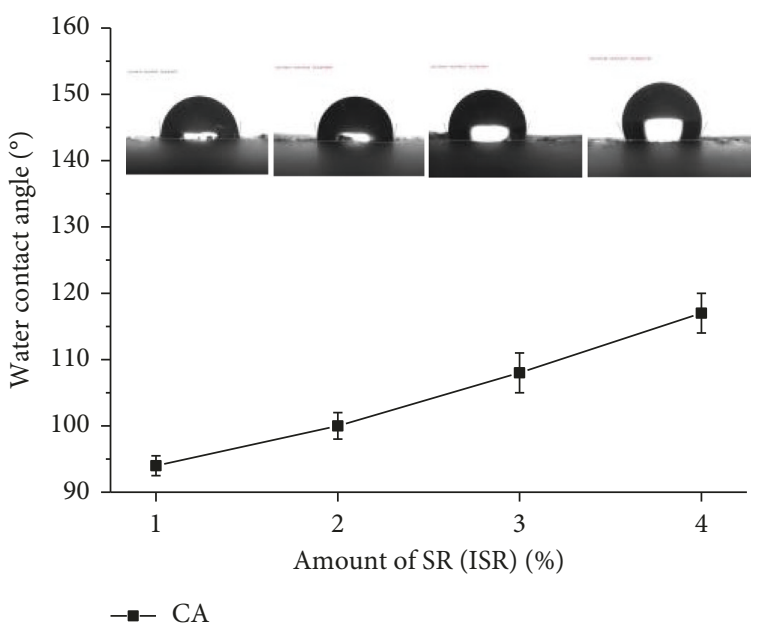

FIGURE 9: Static contact angles of C-ISR.

SSR (e.g., $600 \mathrm{~g} / \mathrm{m}^{2}$ ) in Table 4. The emulsion first existed in the pore solution of concrete; with the further hydration and evaporation of cement, the pore solution gradually decreased, and the SR in the pore solution formed a SR waterproof membrane. The waterproof membrane increases the density of concrete, thus reducing the permeability of the test specimen.

Although it has been reported that the API could be used as an indicator of anticarbonation ability of concrete [39], the estimated criterion should be variable in response to different surface treatment methods because the carbonation depth of concrete was affected not only by its air permeability but also by other factors, such as the alkali content.

\section{Conclusion}

The results of the comprehensive experimental study reported in this paper clarify the effect of SR treatment on the durability of concrete. Based on the result for the containing mechanical properties and relevant durability properties, including capillary absorption, carbonization, and chloride penetration of concrete specimens, the main conclusions are summarized as follows:

(1) SR addition has no effect on the hydration products of cement after 28 days of curing; however, it inhibits the hydration process of cement to a certain extent by obstructing the contact between cement particles and cement. Therefore, SR addition reduces the early compressive and flexural strength of concrete, particularly affecting the compressive strength of concrete. When the content of SR reaches $4 \%$, the compressive strength decreases by $26 \%$, while the flexural strength decreases by only $10 \%$. At the same time, SR can improve the early autogenous shrinkage and drying shrinkage of cement by affecting the hydration process of cement.

(2) Both ISR and SSR can improve the durability of concrete. In contact with hydrostatic water, capillary suction is effectively suppressed both by ISR and SSR. SSR achieves a higher efficiency by sealing the pores on the concrete surface and repelling water from the surface of the test specimen. For C-ISR with $4 \%$ SR 


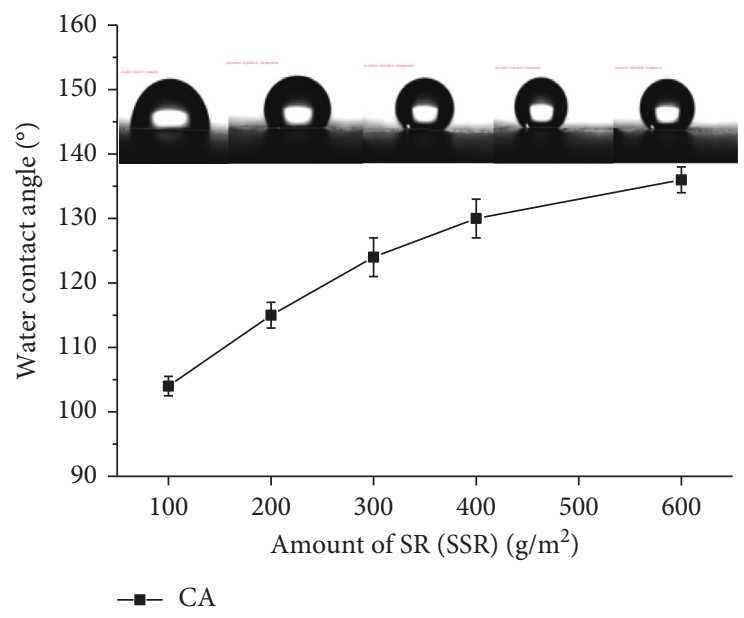

Figure 10: Static contact angles of C-SSR.

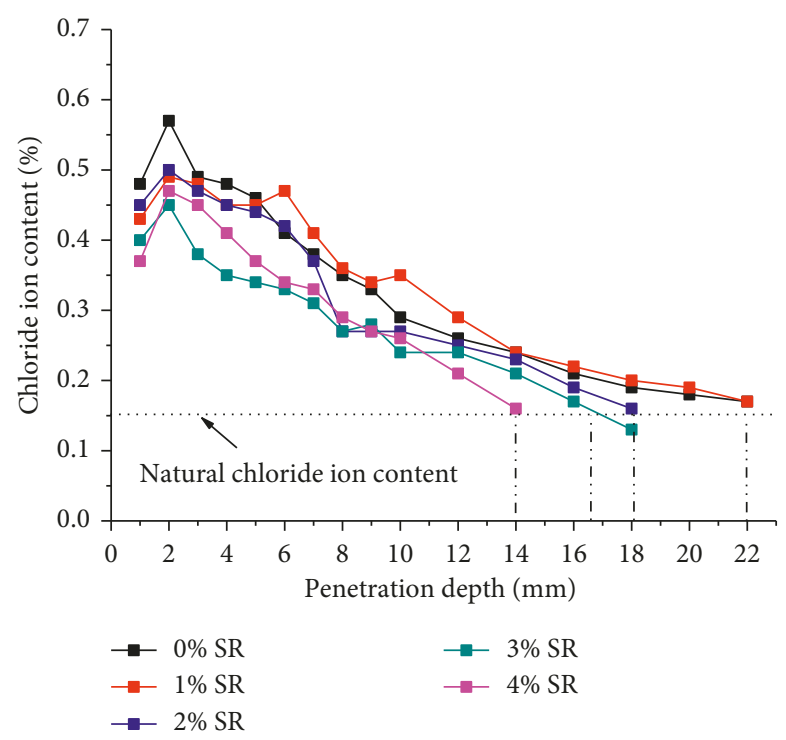

Figure 11: Chloride profiles measured in C-ISR after 28 days of immersion in $0.5 \% \mathrm{NaCl}$.

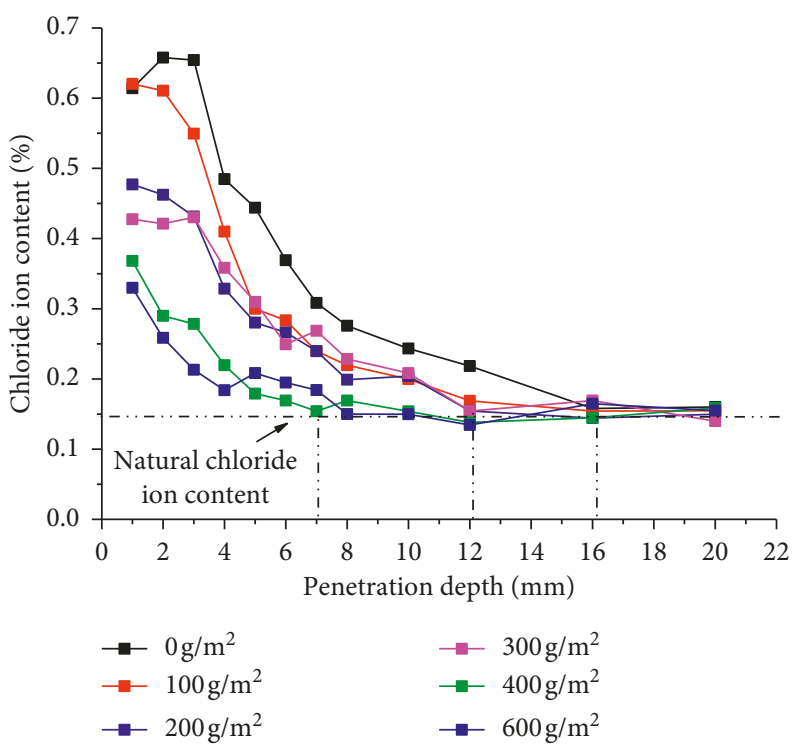

FIgURE 12: Chloride profiles measured in C-SSR after 28 days of immersion in $0.5 \% \mathrm{NaCl}$. 


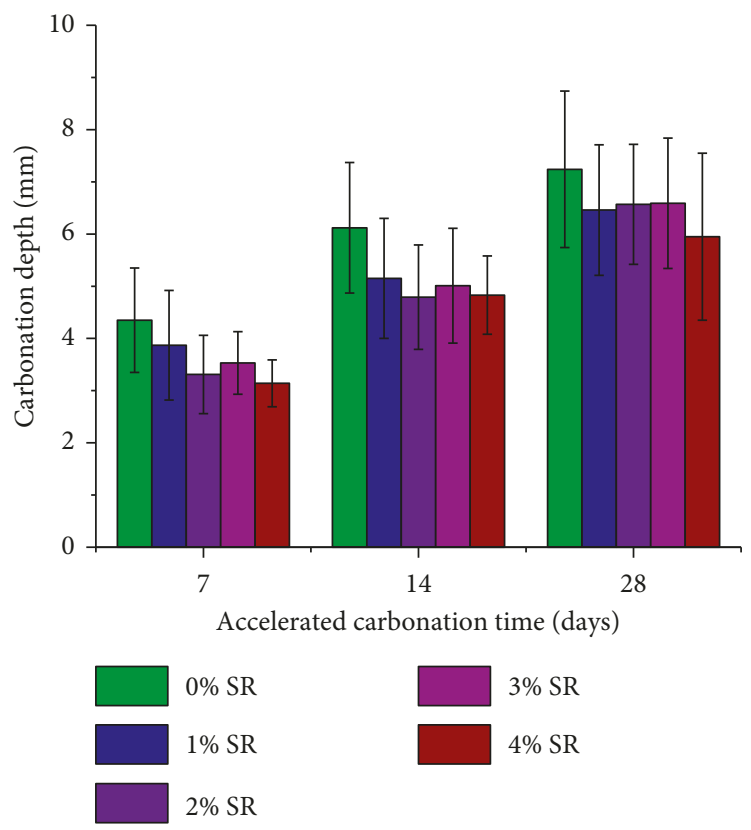

FIGURE 13: Carbonation depth of C-ISR after 7, 14, and 28 days of accelerated carbonation.

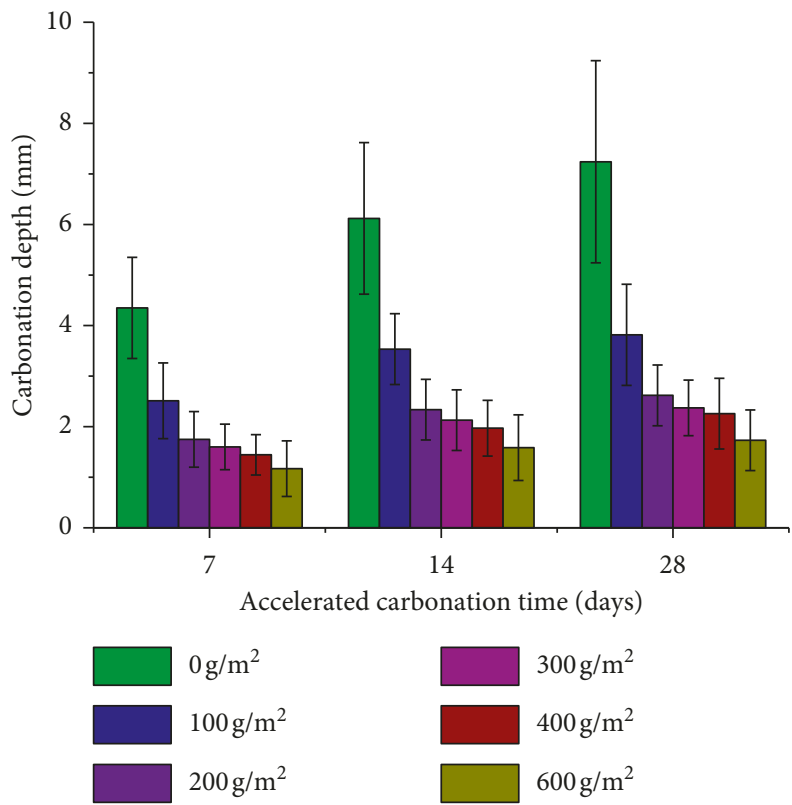

FIGURE 14: Carbonation depth of C-SSR after 7, 14, and 28 days of accelerated carbonation.

TABLE 4: API of specimens with ISR and SSR.

\begin{tabular}{|c|c|c|c|c|c|c|c|c|c|c|}
\hline Specimens & Plain & $1 \%$ & $2 \%$ & $3 \%$ & $4 \%$ & $100 \mathrm{~g} / \mathrm{m}^{2}$ & $200 \mathrm{~g} / \mathrm{m}^{2}$ & $300 \mathrm{~g} / \mathrm{m}^{2}$ & $400 \mathrm{~g} / \mathrm{m}^{2}$ & $600 \mathrm{~g} / \mathrm{m}^{2}$ \\
\hline API (in pressure/min) & 0.0400 & 0.0325 & 0.0328 & 0.0287 & 0.0282 & 0.0308 & 0.0279 & 0.0312 & 0.0248 & 0.0057 \\
\hline Decrease rate (\%) compared to plain & - & 23.7 & 23.1 & 32.6 & 33.8 & 22.1 & 23.5 & 30.6 & 38.2 & 86.0 \\
\hline
\end{tabular}

emulsion, the water absorption speed of concrete is reduced by approximately $50 \%$ compared to the plain concrete. When the surface of the silicone resin was $600 \mathrm{~g} / \mathrm{m}^{2}$, the water absorption rate of the concrete specimen decreased by $91.7 \%$.
(3) With the increasing SR addition, the carbonization depth gradually decreased. However, when the SR emulsion content increased $(2 \%, 3 \%$, or $4 \%)$, the carbonization coefficient of the test coefficient was very close, showing that the anticarbonization ability 
of the SR emulsion is limited. However, SSR showed a marked decrease.

(4) The chloride ion erosion resistance is enhanced by SSR. When the amount of coating is $600 \mathrm{~g} / \mathrm{m}^{2}$, at an age of $28 \mathrm{~d}$, the carbonization depth is decreased by $68.8 \%$, which is about four times higher compared to $4 \%$ addition of SR (18\%). Under identical conditions, the permeability of concrete is more apparent when SR is used.

\section{Data Availability}

The data used to support the findings of this study are available from the corresponding author upon request.

\section{Conflicts of Interest}

The authors declare that they have no conflicts of interest.

\section{Acknowledgments}

The authors acknowledge the financial support from the National Key R\&D Program of China (no. 2017YFB031000405), the National Natural Science Foundation of China (nos. 51608286, U1706222, 51420105015, and 51878254), the Basic Research Program of China (2015CB655100), the Source Innovation Program of Qingdao City Grant (no. 17-1-1-13jch), and the Natural Science Foundation of Shandong Province (ZR2017ZC737).

\section{References}

[1] F. C. Yuan, T. D. Niu, Z. F. Duan et al., "Reach on variation of $\mathrm{pH}$ value of the simulated concrete pore solution during carbonation process," Bulletin of the Chinese Ceramic Society, vol. 35, no. 5, pp. 1126-1130, 2011.

[2] Y. Xian, F. H. Wittmann, T. Zhao, and S. Giessler, "Chloride penetration into integral water repellent concrete/eindringen von chloriden in integral hydrophobierten beton: restoration of buildings and monuments," Restoration of Buildings and Monuments, vol. 13, no. 1, pp. 17-24, 2007.

[3] A. Reinschmidt and M. Roos, "Silicones-essentials for cementitious building materials," Zkg International, vol. 67, no. 12, pp. 60-63, 2014.

[4] P. Zhang, J. T. Zhao, H. F. Wittmann et al., "Preparation and characteristics of integral water repellent cement-based materials," Materials Science Forum, vol. 675-677, pp. 11891192, 2011.

[5] N. Milenkovic, S. Staquet, J. P. Lecomte et al., "Non-ionic silane emulsion as integral water repellent - impact on cement hydration process," in Proceedings of 7th International Conference on Water Repellent Treatment and Protective Surface Technology for Building Materials, Lisbon, Portugal, September 2014.

[6] W. Li, F. H. Wittmann, and T. Zhao, Integral Water Repellent Treatment of Concrete: Production and Properties, Basic Research on Concrete and Applications, Aedificatio Publishers, Breisgau, Germany, 2011.

[7] X.-M. Kong, H. Liu, Z.-B. Lu, and D.-M. Wang, "The influence of silanes on hydration and strength development of cementitious systems," Cement and Concrete Research, vol. 67, no. 18, pp. 168-178, 2015.
[8] L. Falchi, E. Zendri, U. Müller, and P. Fontana, "The influence of water-repellent admixtures on the behaviour and the effectiveness of Portland limestone cement mortars," Cement and Concrete Composites, vol. 59, pp. 107-118, 2015.

[9] H. F. Wittmann, "Integral water repellent concrete by addition of silane emulsion," in Proceedings of International Conference on the Concrete Future, Yantai, China, October 2008.

[10] T. Zhao, H. F. Wittmann, R. Jiang et al., "Application of silane-based compounds for the production of integral water repellent concrete," in Proceedings of Hydrophobe VI, Water Repellent Treatment of Building Materials, Rome, Italy, May 2011.

[11] S. J. Meier and F. H. Wittmann, "Recommendations for water repellent surface impregnation of concrete," Restoration of Buildings \& Monuments, vol. 17, no. 6, pp. 347-358, 2011.

[12] X. Pan, Z. Shi, C. Shi, T.-C. Ling, and N. Li, "A review on concrete surface treatment Part I: types and mechanisms," Construction and Building Materials, vol. 132, pp. 578-590, 2017.

[13] P. Zhang, H. F. Wittmann, B. Villmann et al., "Moisture diffusion in and capillary suction of integral water repellent cement based materials," in Proceedings of Hydrophobe V, Water Repellent Treatment of Building Materials, Brussels, Belgium, April 2008.

[14] G. Cui, J. Liu, C. Chen et al., "Study on silane impregnation for protection of high performance concrete," Procedia Engineering, vol. 27, pp. 301-307, 2012.

[15] F. H. Wittmann, "Increase of service life of reinforced concrete structures in marine environment by water repellent treatment," in Proceedings of International Conference on Advances in Construction Materials through Science and Engineering, Hong Kong, China, September 2011.

[16] Y.-G. Zhu, S.-C. Kou, C.-S. Poon, J.-G. Dai, and Q.-Y. Li, "Influence of silane-based water repellent on the durability properties of recycled aggregate concrete," Cement and Concrete Composites, vol. 35, no. 1, pp. 32-38, 2013.

[17] R. Ganesh and P. Ravikumar, "Polymer modified mortar and concrete present status a review," Journal of Mechanical and Civil Engineering, vol. 13, no. 3, pp. 89-100, 2016.

[18] Y.-h. Zhang, H.-w. Shang, Y. Cai, Z.-h. Hou, G.-f. Zhang, and D.-1. Zhao, "Impacts of melt spinning and element substitution on electrochemical characteristics of the $\mathrm{La}-\mathrm{Mg}-\mathrm{Ni}$ based AB-type Alloys," Advances in Materials Physics and Chemistry, vol. 2, no. 4, pp. 78-83, 2012.

[19] C. M. Neubauer, T. B. Bergstrom, K. Sujata, Y. Xi, E. J. Garboczi, and H. M. Jennings, "Drying shrinkage of cement paste as measured in an environmental scanning electron microscope and comparison with microstructural models," Journal of Materials Science, vol. 32, no. 24, pp. 6415-6427, 1997.

[20] ISO, Hygrothermal Performance of Building Materials and Products-Determination of Water Absorption Coefficient by Partial Immersion, ISO, Geneva, Switzerland, 2002.

[21] S. Brandon and A. Marmur, "Simulation of contact angle hysteresis on chemically heterogeneous surfaces," Journal of Colloid and Interface Science, vol. 183, no. 2, pp. 351-355, 1996.

[22] R. V. Sedev, J. G. Petrov, and A. W. Neumann, "Effect of swelling of a polymer surface on advancing and receding contact angles," Journal of Colloid and Interface Science, vol. 180, no. 1, pp. 36-42, 1996. 
[23] C. Huh and S. G. Mason, "Effects of surface roughness on wetting (theoretical)," Journal of Colloid and Interface Science, vol. 60, no. 1, pp. 11-38, 1977.

[24] C. W. Extrand and Y. Kumagai, "An experimental study of contact angle hysteresis," Journal of Colloid and Interface Science, vol. 191, no. 191, pp. 378-383, 1997.

[25] Y. Shao, V. Rostami, Z. He, and A. J. Boyd, "Accelerated carbonation of Portland limestone cement," Journal of Materials in Civil Engineering, vol. 26, no. 1, pp. 117-124, 2014.

[26] W. Kubissa and M. A. Glinicki, "Influence of internal relative humidity and mix design of radiation shielding concrete on air permeability index," Construction and Building Materials, vol. 147, pp. 352-361, 2017.

[27] T. Matschei, B. Lothenbach, and P. F. Glasser, "The AFm phase in Portland cement," Cement \& Concrete Research, vol. 37, no. 2, pp. 18-130, 2007.

[28] W. Nocuń-Wczelik and P. Czapik, "Use of calorimetry and other methods in the studies of water reducers and set retarders interaction with hydrating cement paste," Construction \& Building Materials, vol. 38, pp. 980-986, 2013.

[29] V. Spaeth, P. M. Delplancke-Ogletree, and P. J. Lecomte, "Hydration Process, microstructure, development of integral water repellent cement based materials," in Proceedings of Hydrophobe V, Water Repellent Treatment of Building Materials, Brussels, Belgium, April 2008.

[30] Y. XI and H. M. Jennings, "Cement-aggregate compatibility and structure property relationships including modelling," Materials science of concrete III, vol. 37, 1992.

[31] W. Hansen, "Drying shrinkage mechanisms in Portland cement paste," Journal of the American Ceramic Society, vol. 70, no. 5, pp. 323-328, 2010.

[32] H. F. Wittmann, "Effective chloride barrier for reinforced concrete structures in marine environment," in Proceedings of Basic Research on Concrete and Applications, Lausanne, Switzerland, July 2011.

[33] G. Moriconi, F. Tittarelli, and V. Corinaldesi, "Review of silicone-based hydrophobic treatment and admixtures for concrete," Indian Concrete Journal, vol. 76, no. 10, pp. 637642, 2002.

[34] E. W. Washburn, "The dynamics of capillary flow," Physical Review, vol. 17, no. 3, pp. 273-283, 1921.

[35] P. Lunk, "Feuchtigkeits- und Schadstoffaufnahme in Feuchtigkeitstransport und Dauerhaftigkeit von Beton," WTA Report Series, vol. 3, pp. 51-78, 1992.

[36] E. Lunk and G. Peter, "Betrachtungen zum feuchtigkeits- nd chloridtransport," in Proceedings of 3rd International Colloquium Materials Science and Restoration, vol. 3, pp. 168-205, Esslingen, Germany, September 1992.

[37] F. Duprat, N. T. Vu, and A. Sellier, "Accelerated carbonation tests for the probabilistic prediction of the durability of concrete structures," Construction and Building Materials, vol. 66, no. 5, pp. 597-605, 2014.

[38] L. Basheer, J. Kropp, and D. J. Cleland, "Assessment of the durability of concrete from its permeation properties: a review," Construction and Building Materials, vol. 15, no. 2, pp. 93-103, 2001

[39] M. Basheer and A. P. Muhammed, Clam Permeability Tests for Assessing the Durability of Concrete, Queen's University of Belfast, Belfast, UK, 1991. 


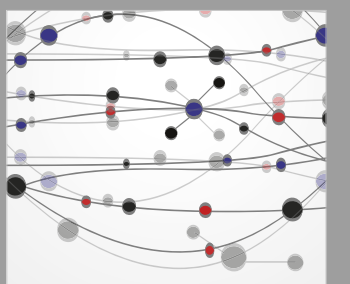

The Scientific World Journal
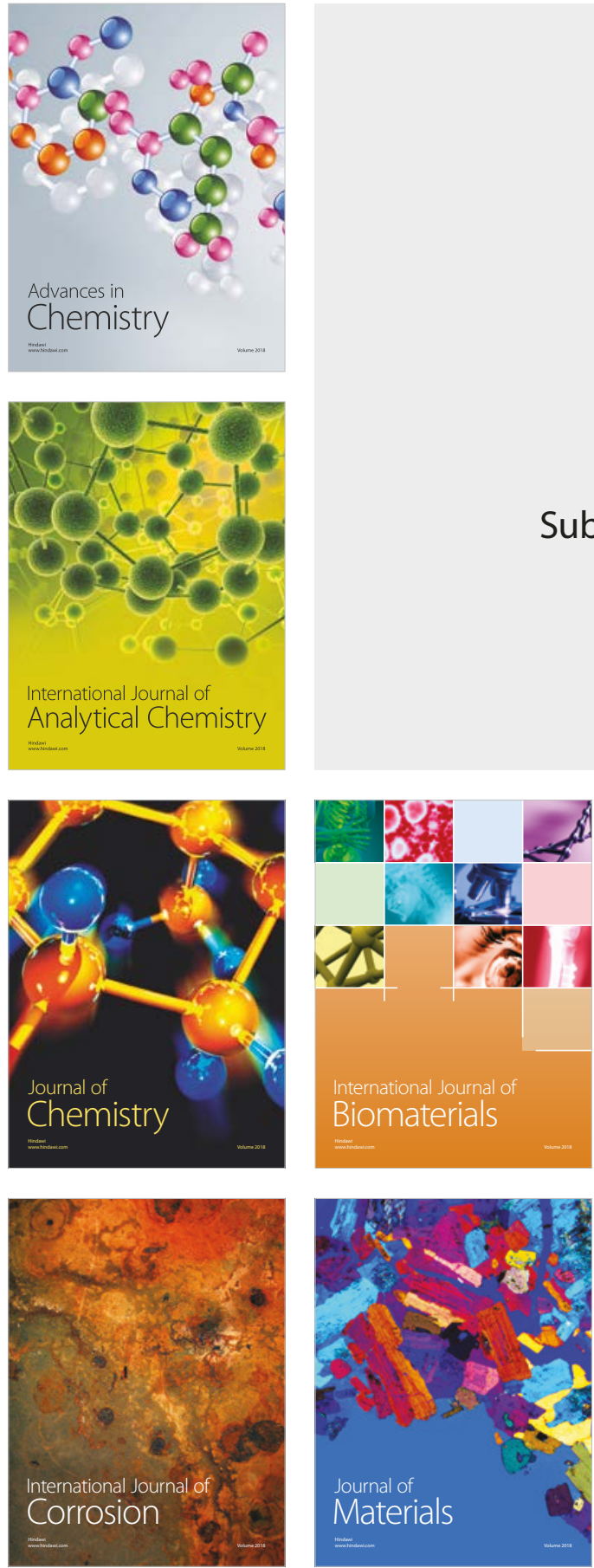

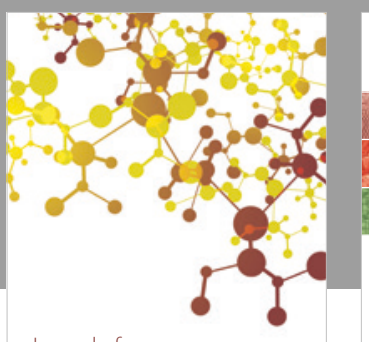

Journal of

Applied Chemistry
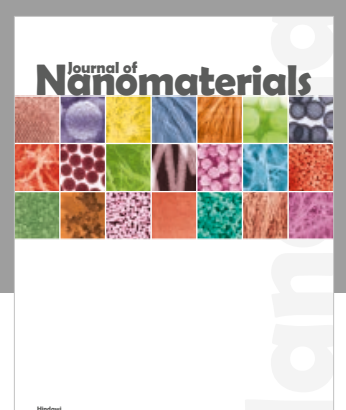

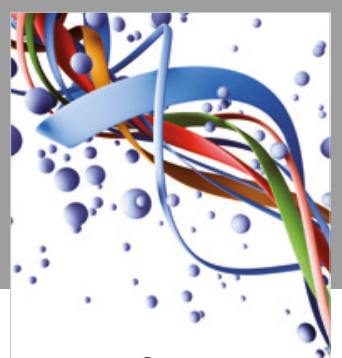

Scientifica

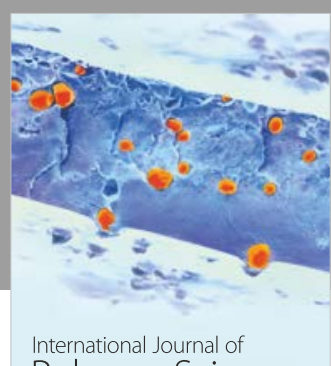

Polymer Science

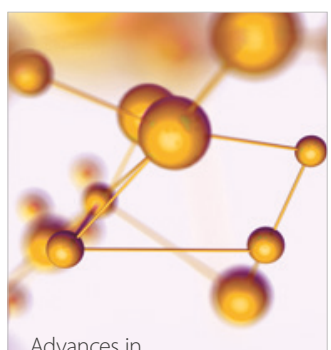

Physical Chemistry
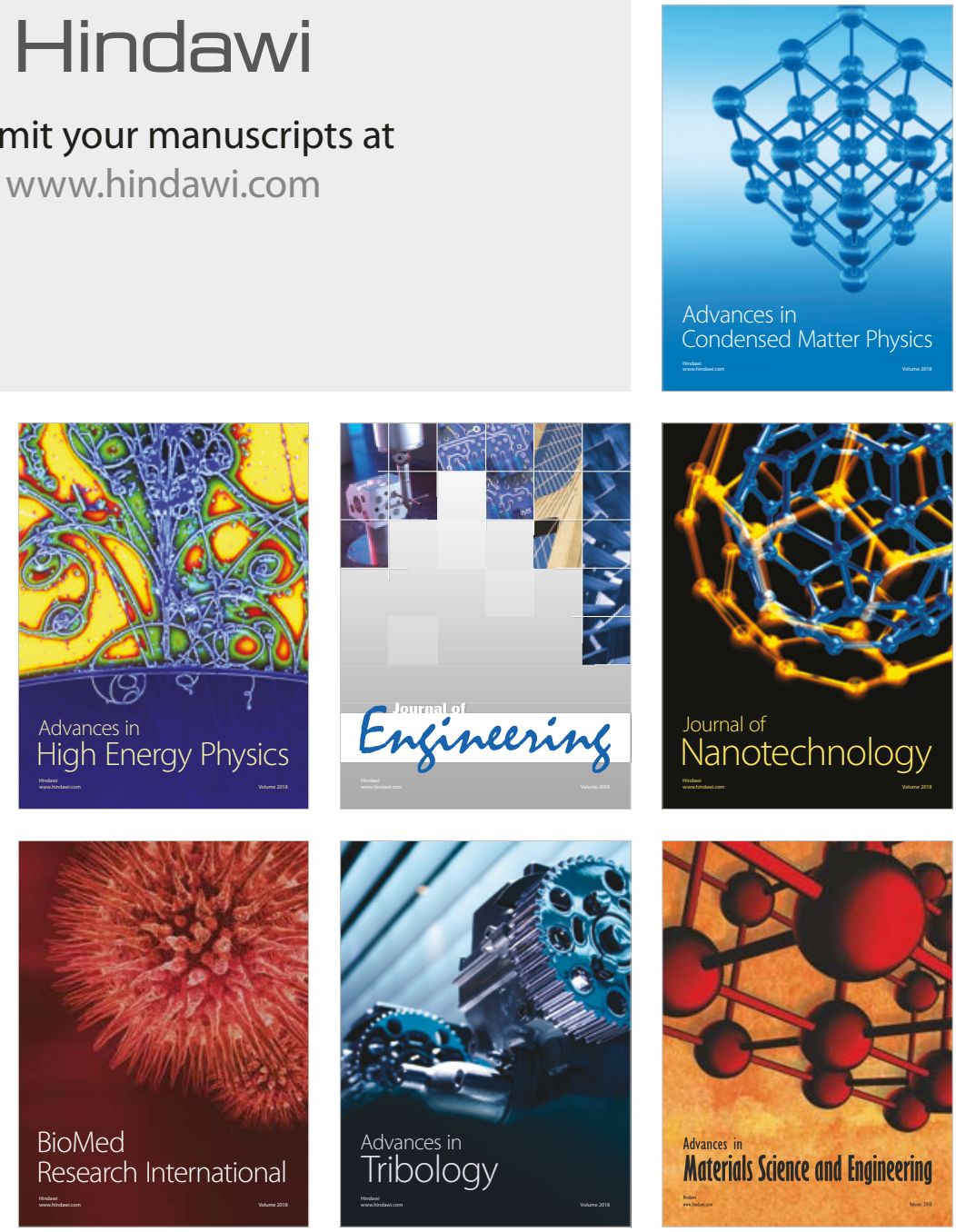